\title{
Effect of mutations in XPD(ERCC2) on pregnancy and prenatal development in mothers of patients with trichothiodystrophy or xeroderma pigmentosum
}

\author{
Deborah Tamura ${ }^{1}$, Sikandar G Khan ${ }^{1}$, Melissa Merideth ${ }^{2}$, John J DiGiovanna ${ }^{1}$, Margaret A Tucker ${ }^{3}$, \\ Alisa M Goldstein ${ }^{3}$, Kyu-Seon $\mathrm{Oh}^{1}$, Takahiro Ueda ${ }^{1}$, Jennifer Boyle ${ }^{1}$, Mansi Sarihan ${ }^{1,4}$ and Kenneth H Kraemer ${ }^{\star}, 1$
}

The $X P D(E R C C 2)$ gene encodes a DNA helicase involved in DNA repair and transcription. Patients with mutations in XPD may have different autosomal recessive phenotypes including trichothiodystrophy (TTD) or xeroderma pigmentosum (XP). TTD patients have sulfur-deficient, brittle hair, short stature and developmental delay. In contrast, XP patients have freckle-like pigmentation and a greatly increased risk of sun-induced skin cancers. Mothers of TTD patients have been reported to have a high frequency of pregnancy and neonatal complications. We performed a molecular epidemiological study of 15 mothers of 17 TTD patients and 13 mothers of 17 XP patients, all with XPD mutations. We found that 94\% (16/17) of the TTD pregnancies had pre-term delivery, pre-eclampsia, hemolysis, elevated liver enzymes and low platelets (HELLP) syndrome, prematurity or low birth weight. None of the 17 XP pregnancies had these complications $(P<0.001)$. As mutations in XPD may have differential effects on DNA repair and transcription, these observations should provide insights into the role of $X P D$ in human pregnancy and fetal development.

European Journal of Human Genetics (2012) 20, 1308-1310; doi:10.1038/ejhg.2012.90; published online 23 May 2012

Keywords: DNA repair; pre-eclampsia; transcription factor IIH

\section{INTRODUCTION}

Patients with different mutations in the DNA repair/transcription helicase, XPD(ERCC2), may have markedly disparate autosomal recessive phenotypes, including trichothiodystrophy (TTD) or xeroderma pigmentosum (XP). ${ }^{1-11}$ TTD patients have brittle hair, short stature, developmental delay and multisystem involvement without increased skin cancer risk. ${ }^{12}$ In contrast, XP patients have sun sensitivity, freckle-like skin pigmentation, a 10000 -fold increase in skin cancer, and $25 \%$ have progressive neurologic degeneration. ${ }^{12,13}$ At the National Institutes of Health (NIH), we have examined XP patients since 1971 and TTD patients since 2001 as part of a natural history protocol. ${ }^{7,13}$

Our review of all English-language-published case reports of TTD patients found 112 TTD patients, of whom 55\% had abnormal characteristics at birth and $28 \%$ had maternal pregnancy complications. ${ }^{14}$ We then conducted two molecular epidemiological studies of pregnancy and neonatal abnormalities in mothers of TTD patients in our clinic. ${ }^{15,16}$ We found that $81 \%$ of these pregnancies had complications, including 56\% with preterm delivery, 30\% with preeclampsia and $11 \%$ with hemolysis, elevated liver enzymes and low platelets (HELLP) syndrome. ${ }^{16}$ The TTD patients had mutations in TTD-A(GTF2H5) or TTDN1(C7orf11) in addition to XPD and unknown genes. In contrast, our 1987 review of all Englishlanguage-published case reports of XP patients did not identify a large number of pregnancy abnormalities in $830 \mathrm{XP}$ case reports. ${ }^{17}$
These patients had mutations in at least 8 different genes involved in nucleotide excision repair and polymerase function. ${ }^{7}$ In order to determine the influence of the XPD gene, we now have conducted a molecular epidemiological study of pregnancy and neonatal abnormalities in the mothers of the XP patients with XPD mutations in our protocol. We compared these new data to that of the mothers of the TTD patients with XPD mutations from our earlier studies ${ }^{15,16}$ and found large differences.

\section{MATERIALS AND METHODS}

We performed a systematic study of the mothers of the XP patients enrolled in our NIH protocol using the same methods that we used for study of the mothers of TTD patients. ${ }^{15,16}$ In short, we examined XP-affected children's pediatric records and noted birth weights and lengths, evidence of abnormal characteristics at birth and need for NICU admission. We specifically questioned the mothers of XP patients with XPD mutations in our protocol ${ }^{13}$ regarding their pregnancies either in person during the NIH evaluation or by follow-up phone call or e-mail. We inquired about the length of gestation, presence of hypertensive disorders during the pregnancy and any newborn complications in the XP-affected offspring.

\section{RESULTS}

Mutations in the XPD gene were present in 17 of the TTD patients in our studies ${ }^{15,16}$ (Table 1). Ninety-four percent (16/17) of these TTD pregnancies with $X P D$ mutations had pregnancy and/or neonatal complications. Eighty-eight percent were admitted to the neonatal

${ }^{1}$ Dermatology Branch, Center for Cancer Research, National Cancer Institute, Bethesda, MD, USA; ${ }^{2}$ Medical Genetics Branch, National Human Genome Research Institute and Intramural Office of Rare Diseases, Bethesda, MD, USA; ${ }^{3}$ Genetic Epidemiology Branch, DCEG, National Cancer Institute, Bethesda, MD, USA; ${ }^{4}$ Cancer Research and the Division of Cancer Epidemiology and Genetics, National Cancer Institute, NIH, Bethesda, MD, USA

*Correspondence: Dr KH Kraemer, Dermatology Branch, Center for Cancer Research, National Cancer Institute, Building 37, Room 4002, MSC 4258, Bethesda, MD 208924258, USA. Tel: +1-301-496-9033; Fax: +1-301-594-3409; E-mail: kraemerk@nih.gov

Received 15 February 2012; revised 6 April 2012; accepted 12 April 2012; published online 23 May 2012 
Table 1 Pregnancy and neonatal complications in mothers of TTD or $\mathrm{XP}$ patients with XPD mutations

\begin{tabular}{|c|c|c|c|}
\hline & $\begin{array}{c}T T D^{a} \\
\text { (number) }\end{array}$ & $\begin{array}{c}X P^{b} \\
\text { (number) }\end{array}$ & $\mathrm{P}$ value \\
\hline$X P D$ mothers ${ }^{c}$ & 15 & 13 & NS \\
\hline Patients/pregnancies with $X P D$ mutations (total) & 17 & 17 & NS \\
\hline Pregnancies with complications ${ }^{d}$ & 15 & 0 & $<0.0001$ \\
\hline Neonates with complications ${ }^{\mathrm{e}}$ & 14 & 0 & $<0.0001$ \\
\hline Any pregnancy or neonatal complication & 16 & 0 & $<0.0001$ \\
\hline NICU admission & $15^{f}$ & $2^{g}$ & $<0.0001$ \\
\hline
\end{tabular}

aFrom Moslehi et al ${ }^{15}$ and Tamura et al 16 excluding four patients with XP/TTD from one mother and one patient with COFS/TTD.

bThis report.

'Obligate heterozygotes.

Pre-term delivery, pre-eclampsia or HELLP syndrome.

eLow birth weight or small for gestational age.

fPrematurity or low birth weight (see text).

ABO incompatibility; meningitis (see text)

intensive care unit (NICU) primarily for problems related to prematurity and low birth weight.

Since 1971, we examined 23 XP patients with XPD mutations at $\mathrm{NIH} .{ }^{13}$ We were able to contact 13 mothers of 17 of these XP patients (Table 1). None of the pregnancies with XP-affected children had symptoms of pre-eclampsia, HELLP syndrome, pre-term delivery, low birth weight or small for gestational age. However, two XP neonates were admitted to the NICU. One had ABO incompatibility, which occurs in approximately $6.9 \%$ of normal pregnancies. ${ }^{18}$ The second XP infant initially did well after birth, but was admitted to the NICU at 10 days of age secondary to developing streptococcal meningitis. Neither of these complications was noted in the TTD neonates.

These differences in pregnancy or neonatal complications between pregnancies with defects in XPD resulting in TTD-affected children (16/17 with complications) or in XP-affected children (0/17 with complications) are statistically significant $(P<0.0001)$ (Table 1$)$. The frequency of NICU admissions among XP neonates was smaller $(P<0.0001)$ than for TTD neonates.

\section{DISCUSSION}

Moslehi et $a l^{19}$ recently reported a literature review of the relationship of mutations in the DNA repair/transcription gene, $X P D$, with human prenatal development. They claim 'Gestational complications were first reported to be ... associated with TTD based on our novel clinical observations.... However, Pollit et al ${ }^{20}$ described gestational complications including toxemia of pregnancy in 1968. In addition, in attempting to evaluate the analysis by Moslehi and colleagues associating mutations in the C-terminal motif of XPD with TTD prenatal complications, we were unable to find mutation information in two of the three references cited. ${ }^{15,21}$

Our XP and TTD patients had XPD mutations that are similar to those previously published. ${ }^{1,5,8-11}$ All of our XP and TTD patients were compound heterozygotes for two different XPD mutations. Many XP patients had the common p.R683W mutation combined with other mutations. ${ }^{2,5,6}$ In the TTD patients, the mutations involve the C-terminal region (p.A725T in TTD421BE, p.E731Rfs ${ }^{\star} 14$ in TTD355BE and p.R722W in TTD351BE) as well as other locations in the XPD protein. ${ }^{2,22}$ The pregnancies yielding patients TTD421BE and TTD355BE had pre-eclampsia, but the pregnancy yielding patient TTD351BE did not have pre-eclampsia. ${ }^{16}$ Thus, mutations in the C-terminal region of the XPD protein are not always associated with pre-eclampsia. Perhaps the outcome is influenced by which allele is maternal and which is paternal in these pregnancies.
There are several reasons why we believe that the prediction by Moslehi et al ${ }^{19}$ that mutations in the C-terminal region of $\mathrm{XPD}^{8-10}$ cause pre-eclampsia may not be correct. There is a complex genotype-phenotype relationship between the location of mutations in the human XPD gene and the presence or absence of clinical features of XP or TTD. Mutations are spread out along the 761 amino-acid structure of XPD in both disorders ${ }^{1,5,8-11}$ The mutations may affect nucleotide-excision repair and/or transcription to different extents. $^{2,3}$ In addition, some mutations are found in both XP and TTD patients. As XPD is an essential part of the basal transcription factor TFIIH, complete absence of this protein is not compatible with life. Some alleles have been considered as null, with no activity for some functions. ${ }^{5}$ However, XPD has multiple functions and there is evidence that both XPD alleles contribute to the overall phenotype. ${ }^{6}$

We previously reported on a patient with COFS/TTD (TTD373BE) having p.D681N and p.R616W mutations that were not in the C-terminal region but were near the common p.R683W XP-associated mutation. ${ }^{23}$ The pregnancy had pre-eclampsia, HELLP syndrome, preterm delivery and low birth weight. ${ }^{15}$ An infant reported to have COFS syndrome had these same two XPD mutations and was born at 37 weeks, weighing only $1.4 \mathrm{~kg} .{ }^{24}$ However, these authors did not report pregnancy-related abnormalities or whether the hair of this patient had the typical features of TTD (tiger-tail banding with polarized microscopy ${ }^{12}$ ), hence we do not know if this patient also had COFS/TTD. COFS is closely related to Cockayne syndrome (CS) type II and both may be associated with low birth weight. ${ }^{25-27}$ COFS can be caused by mutations in several nucleotide excision repair genes: $C S B$ (ERCC6), XPG(ERCC5), or ERCC1 in addition to XPD. ${ }^{25}$ However, a comprehensive literature review of 140 CS cases did not report severe pregnancy complications in any of the forms of CS. ${ }^{27}$

Because most TTD and XP patients are compound heterozygotes, it is difficult to ascribe a clinical phenotype to a single mutation. As TTD is an autosomal recessive disorder, the mothers of the XPDaffected patients are obligate heterozygotes. Specific maternal mutations may influence the risk for prenatal complications. If the embryo is affected, then the developing fetus and the placenta also have a second mutated allele, resulting in a high frequency of pregnancy abnormalities. In contrast, in XP-affected pregnancies the XPD mutations are not associated with pregnancy complications. Thus, there appears to be specificity in the effects of the mutations in the XPD gene leading to pre-eclampsia, HELLP syndrome and impaired neonatal development. As mutations in XPD may have differential effects on DNA repair ${ }^{2}$ and on transcription, ${ }^{3}$ these observations should provide insights into the role of XPD in human pregnancy and fetal development.

\section{CONFLICT OF INTEREST}

The authors declare no conflict of interest.

\section{ACKNOWLEDGEMENTS}

This work was supported by the intramural research program of the Center for Cancer Research and the Division of Cancer Epidemiology and Genetics, National Cancer Institute, NIH, Bethesda, MD, USA. Ms Sarihan was supported by the Clinical Research Training Program, a public-private partnership supported jointly by the NIH and Pfizer, Inc. (via a grant to the Foundation for NIH from Pfizer, Inc.).

\footnotetext{
1 Botta E, Nardo T, Broughton BC, Marinoni S, Lehmann AR, Stefanini M: Analysis of mutations in the XPD gene in Italian patients with trichothiodystrophy: site of mutation correlates with repair deficiency, but gene dosage appears to determine clinical severity. Am J Hum Genet 1998; 63: 1036-1048.
} 
2 Boyle J, Ueda T, Oh KS et al: Persistence of repair proteins at unrepaired DNA damage distinguishes diseases with ERCC2 (XPD) mutations: cancer-prone xeroderma pigmentosum vs. non-cancer-prone trichothiodystrophy. Hum Mutat 2008; 29: 1194-1208.

3 Dubaele S, Proietti dS, Bienstock RJ et al: Basal transcription defect discriminates between xeroderma pigmentosum and trichothiodystrophy in XPD patients. Mol Cell 2003; 11: 1635-1646.

4 Egly JM, Coin F: A history of TFIIH: two decades of molecular biology on a pivotal transcription/repair factor. DNA Repair (Amst) 2011; 10: 714-721.

5 Taylor EM, Broughton BC, Botta E et al: Xeroderma pigmentosum and trichothiodystrophy are associated with different mutations in the XPD (ERCC2) repair/transcription gene. Proc Natl Acad Sci USA 1997; 94: 8658-8663.

6 Ueda T, Compe E, Catez P, Kraemer KH, Egly JM, Both XPD: alleles contribute to the phenotype of compound heterozygote xeroderma pigmentosum patients. J Exp Med 2009; 206: 3031-3046.

7 DiGiovanna JJ, Kraemer KH: Shining a Light on Xeroderma Pigmentosum. J Invest Dermatol 2012

8 Fan L, Fuss JO, Cheng QJ et al: XPD helicase structures and activities: insights into the cancer and aging phenotypes from XPD mutations. Cell 2008; 133: 789-800.

9 Liu H, Rudolf J, Johnson KA et al: Structure of the DNA repair helicase XPD. Cell 2008; 133: 801-812.

10 Wolski SC, Kuper J, Hanzelmann $P$ et al: Crystal structure of the FeS clustercontaining nucleotide excision repair helicase XPD. PLOS Biol 2008; 6: e149.

11 Lehmann AR: The xeroderma pigmentosum group $D$ (XPD) gene: one gene, two functions, three diseases. Genes Dev 2001; 15: 15-23.

12 Kraemer KH, Patronas NJ, Schiffmann R, Brooks BP, Tamura D, DiGiovanna JJ: Xeroderma pigmentosum, trichothiodystrophy and Cockayne syndrome: A complex genotype-phenotype relationship. Neuroscience 2007; 145: 1388-1396.

13 Bradford PT, Goldstein AM, Tamura D et al: Cancer and neurologic degeneration in xeroderma pigmentosum: long term follow-up characterises the role of DNA repair. J Med Genet 2011; 48: 168-176.

14 Faghri S, Tamura D, Kraemer KH, DiGiovanna JJ: Trichothiodystrophy: a systematic review of 112 published cases characterises a wide spectrum of clinical manifestations. J Med Genet 2008; 45: 609-621.

15 Moslehi R, Signore C, Tamura D et al: Adverse effects of trichothiodystrophy DNA repair and transcription gene disorder on human fetal development. Clin Genet 2010; 77: 365-373.
16 Tamura D, Merideth M, DiGiovanna JJ et al: High-risk pregnancy and neonata complications in the DNA repair and transcription disorder trichothiodystrophy: report of 27 affected pregnancies. Prenat Diagn 2011; 31: 1046-1053.

17 Kraemer KH, Lee MM, Scotto J: Xeroderma pigmentosum. Cutaneous, ocular, and neurologic abnormalities in 830 published cases. Arch Dermatol 1987; 123 241-250.

18 Ozolek JA, Watchko JF, Mimouni F: Prevalence and lack of clinical significance of blood group incompatibility in mothers with blood type A or B. J Pediatr 1994; 125 87-91.

19 Moslehi R, Kumar A, Mills JL, Ambroggio X, Signore C, Dzutsev A: Phenotypespecific adverse effects of XPD mutations on human prenatal development implicate impairment of TFIIH-mediated functions in placenta. Eur J Hum Genet 2012; e-pub ahead of print 11 January 2012; doi:10.1038/ejhg.2011.249.

20 Pollitt RJ, Jenner FA, Davies M: Sibs with mental and physical retardation and trichorrhexis nodosa with abnormal amino acid composition of the hair. Arch Dis Child 1968; 43: 211-216.

21 Stefanini M, Lagomarsini P, Arlett CF et al: Xeroderma pigmentosum (complementation group D) mutation is present in patients affected by trichothiodystrophy with photosensitivity. Hum Genet 1986; 74: 107-112.

22 Zhou X, Khan SG, Tamura D et al: Brittle hair, developmental delay, neurologic abnormalities, and photosensitivity in a 4-year-old girl. J Am Acad Dermatol 2010; 63: 323-328.

23 Sarihan M, Khan SG, Mendelsohn NJ et al: Trichothiodystrophy patients with XPD mutations and features of COFS or features of Cockayne syndrome. J Invest Dermatol 2009; 129: S103.

24 Graham Jr. JM, Anyane-Yeboa K, Raams A et al: Cerebro-oculo-facio-skeletal syndrome with a nucleotide excision-repair defect and a mutated XPD gene, with prenatal diagnosis in a triplet pregnancy. Am J Hum Genet 2001; 69: 291-300.

25 Laugel V, Dalloz C, Tobias ES et al: Cerebro-oculo-facio-skeletal syndrome: three additional cases with CSB mutations, new diagnostic criteria and an approach to investigation. J Med Genet 2008; 45: 564-571.

26 Laugel V, Dalloz C, Durand $M$ et al: Mutation update for the CSB/ERCC6 and CSA/ERCC8 genes involved in Cockayne syndrome. Hum Mutat 2010; 31 113-126.

27 Nance MA, Berry SA: Cockayne syndrome: review of 140 cases. Am J Med Genet 1992; 42: 68-84 